\title{
Formative Assessment of Multimedia Assisted Instruction in College English Listening and Speaking
}

\author{
Wei Wei \\ School of Foreign Languages \\ Northwest Minzu University \\ Lanzhou, China \\ 1sslv@126.com
}

\begin{abstract}
The purpose of the study is to discuss the operation processes and the effect of application of formative assessment with multimedia assisted instruction in College English listening and speaking. The operation processes of formative assessment with multimedia assisted instruction are discussed qualitatively and its effect of application is analyzed quantitatively. This paper reach conclusions that the operation processes of formative assessment with multimedia assisted instruction may include the following three parts: self-assessment, peer assessment, and teacher assessment, and the application of formative assessment with multimedia assisted instruction has significant effect on College English listening and speaking.
\end{abstract}

Keywords-Formative assessment; Multimedia assisted instruction; Self-assessment; Peer assessment; Teacher assessment

\section{INTRODUCTION}

Formative assessment is a series of formal and informal assessment modes carried out by teachers in the process of learning. The purpose is to improve teaching and learning activities in order to improve student achievements [1]. It is usually involved in high-quality feedback instead of scores for both students and teachers. The feedback pays attention to the details of teaching contents and practice [2]. It is usually compared with summative assessment, which is usually designed to monitor educational results, usually for external purposes [3].

There are a variety of objectives for formative assessment. It offers feedback for teachers to correct following learning activities and focuses on the identification and correction of group or individual defects [2]. It keeps attention away from achievements and learning process to improve self-efficacy, reduce the negative effects of external motivation, and improve the metacognitive awareness of students' learning [3]. This type of frequent and continuous assessment can not only make teaching fine, but also enable students to pay attention to their progress [4].

According to Harlen and James [5], formative assessment has several features. In essence, it has a positive intention of promoting learning; therefore, it is part of teaching. It takes into consideration the progress of each student, the endeavors devoted and other aspects of learning, which may not be specified in the course. It must consider certain situation, in which some strategies are employed, and there will be contradiction in implementation and results. Such contradiction will be "wrong" in summative assessment, but in formative assessment, it produces diagnostic information. Effectiveness and usefulness are the primary contents of formative assessment, and priority should be given to reliability. More importantly, formative assessment requires students to be active in their own studies. They will not make progress unless they get the picture of their strengths and weaknesses, and what to do with them.

Feedback is the core part of formative assessment. It usually involves focusing on the details of what is being learned [2], rather than simple test scores or the places in the class [6]. David and Debra [6-7] synthesized the several principles of good feedback. It illuminates the good goals, standards, expectation standards, promotes the development of self-evaluation of learning, provides students with high quality learning information, encourages teachers and peers to engage in dialogue about learning, encourages positive motivation and self-esteem, provides the chances to narrow the gap between current and expected effects, and provides teachers with information for helping teaching.

While there are many studies on formative assessment in college English listening and speaking courses in China, there are rare studies on formative assessment with multimedia assisted instruction (MAI) and the special subjects in ethnic universities. Because the majority of students in ethnic universities come from minority areas, the different areas and subjects are bound to have different requirements for the research methods and the research process. The purpose of this study is to employ formative assessment in English listening and speaking teaching and to test the effect of application of formative assessment.

\section{METHODS}

The subjects of this study come from Northwest Minzu University, Gansu Province. The English level of these students is medium. There is a common sense that students in Minzu universities are not good at English learning. Therefore, the English level of medium students in Minzu universities may be lower than that of medium students in other universities. The two classes are randomly assigned to be the experimental group and the control group. There are 55 students in the experimental group (EG) and 50 in the control group (CG).

This work was financially supported by Central Government Special Funds for Northwest Minzu University (Grant No. 31920130078). 


\section{- Teacher assessment}

Students' self-assessment and peer assessment must be combined with the assessment of the teacher. When evaluating the students, teachers show students the methods of evaluation on the multimedia platform and help them to evaluate themselves. When students make and apply evaluation criteria, teachers must give guidance. More importantly, teachers should discuss the purpose of learning with students, evaluate students' progress regularly, and examine their self-determination carefully [10].

\section{A. The Operation Processes of Formative Assessment with MAI}

Formative assessment is evaluation of students' learning process, aiming at identifying students' potential, improving and developing students, learning. The task of formative assessment is to evaluate the development of students' performance in the course of their daily learning, the achievements they have achieved, as well as the development of their emotions, attitudes and strategies. The purpose is to motivate students to learn, to help students to effectively control their learning process, to achieve a sense of achievement, to enhance self-confidence and to foster a spirit of cooperation. In the formative assessment, the responsibility of the teacher is to determine the task, collect materials, guide and discuss with the students, and evaluate with the students. Therefore, the operation processes of formative assessment with MAI can contain three parts---self-assessment, peer assessment, and teacher assessment.

\section{- Self-assessment}

Self-assessment mainly aims to students' evaluation and understanding of their learning strategies, efforts and learning effectiveness. Students' evaluation of their learning process is a sense of responsibility for formative learning and can form an individual's unique and effective learning method and an important way to improve their learning ability [8]. For example, with the help of MAI, students can evaluate their activities of whether the class will listen carefully, whether they are active in the classroom activities, and whether they can speak the words and sentences loudly, rhythmically and fluently.

\section{- Peer assessment}

Peer assessment is the evaluation of the learning conditions, processes and effects in the course of teaching, on the basis of the independent learning group, according to the criteria of evaluation [9]. On a multimedia platform, four or five students can be allowed to evaluate a student, and each evaluator writes comments for a student's learning behavior, focusing on good performance and suggestions for improvement. On the contrary, the students who have been evaluated write a summary according to the comments of their classmates and teachers, and confirm their own improvement plan. Each student can read the comments on the multimedia platform. Mutual reviews encourage students to cooperate and learn from others. Mutual discussion among students can eliminate their worries and problems and absorb the advantages of others

\section{B. The Effect of Application of Formative Assessment with MAI}

In EG English listening and speaking class, students are guided to perform the formative assessment. Students' assessments can be shown on a multimedia platform. The traditional teaching methods are employed in the CG English listening and speaking class. Questionnaires about the effects of types of assessments with 7-point Likert scale are conducted before and after the experiment. Table 1 shows T-test results of data of assessments compared in EG and CG.

TABLE I. ASSESSMENTS COMPARED IN EG AND CG

\begin{tabular}{|c|c|c|c|c|c|c|}
\hline Type & Test & Group & $\mathbf{M}$ & SD & $\mathbf{t}$ & $\mathbf{p}$ \\
\hline \multirow{2}{*}{ SA } & Pretest & $\begin{array}{l}\text { EG } \\
\text { CG }\end{array}$ & $\begin{array}{l}3.58 \\
3.30\end{array}$ & $\begin{array}{l}1.117 \\
1.129\end{array}$ & 1.284 & .202 \\
\hline & Posttest & $\begin{array}{l}\text { EG } \\
\text { CG }\end{array}$ & $\begin{array}{l}4.65 \\
3.38\end{array}$ & $\begin{array}{c}.985 \\
1.086\end{array}$ & 6.306 & .000 \\
\hline \multirow{2}{*}{ PA } & Pretest & $\begin{array}{l}\text { EG } \\
\text { CG }\end{array}$ & $\begin{array}{l}3.55 \\
3.42\end{array}$ & $\begin{array}{l}1.086 \\
1.090\end{array}$ & .590 & .556 \\
\hline & Posttest & $\begin{array}{l}\text { EG } \\
\text { CG }\end{array}$ & $\begin{array}{l}4.56 \\
3.54\end{array}$ & $\begin{array}{l}1.014 \\
1.034\end{array}$ & 5.117 & .000 \\
\hline \multirow{2}{*}{ TA } & Pretest & $\begin{array}{l}\text { EG } \\
\text { CG }\end{array}$ & $\begin{array}{l}3.89 \\
3.66\end{array}$ & $\begin{array}{l}.916 \\
.982\end{array}$ & 1.247 & .215 \\
\hline & Posttest & $\begin{array}{l}\text { EG } \\
\text { CG }\end{array}$ & $\begin{array}{l}5.04 \\
3.68\end{array}$ & $\begin{array}{l}.838 \\
.999\end{array}$ & 7.561 & .000 \\
\hline
\end{tabular}

$\mathrm{M}=$ mean, $\mathrm{SD}=$ standard deviation

Before the experiment, students' ideas about the three types of assessments are the same because the p-values $(0.202$ for SA, 0.556 for PA, and 0.215 for TA) of the pretests are all higher than 0.05 . However, their ideas become significantly different in the posttests with all $\mathrm{p}$-values smaller than 0.05 . The means (M) of the three types of assessments in posttests are all significantly higher than those in pretests in EG, but the means are almost the same in posttests and pretests in CG. The difference of standard deviation (SD) is not very great for all the posttests and pretests.

The means of the three types of assessments in pretests show that students' recognition on assessments is not very high because all the means are less than 4. However, EG students' recognition on assessments is higher in posttests than that for CG students.

Table 2 displays T-test results of data of assessments compared in pretest and posttest. The mean differences of the three types of assessments in pretest and posttest for EG are significantly higher than those for CG $(p<0.05)$. However, the mean difference of the teacher assessment in pretest and 
posttest for EG is relatively higher than that of self-assessment or peer assessment, which means that students prefer believing in their teacher and make progress with the help of the teacher assessment.

The assessment between the pretest and the posttest in either EG or CG is significantly correlated, which means that students are consistent in recognition on every type of assessments.

TABLE II. ASSESSMENTS COMPARISON OF PRETEST AND POSTTEST

\begin{tabular}{|c|c|c|c|c|}
\hline Type & Group & Test & Mean Difference & Correlation \\
\hline \multirow{3}{*}{ SA } & EG & $\begin{array}{c}\text { Pretest } \\
\text { Posttest }\end{array}$ & $-1.073^{*}$ & $.657^{*}$ \\
\cline { 2 - 5 } & CG & $\begin{array}{c}\text { Pretest } \\
\text { Posttest }\end{array}$ & -.080 & $.804^{*}$ \\
\hline \multirow{2}{*}{ PA } & EG & $\begin{array}{c}\text { Pretest } \\
\text { Posttest }\end{array}$ & $1.018^{*}$ & $641^{*}$ \\
\cline { 2 - 5 } & CG & $\begin{array}{c}\text { Pretest } \\
\text { Posttest }\end{array}$ & .120 & $791^{*}$ \\
\hline \multirow{2}{*}{ TA } & EG & $\begin{array}{c}\text { Pretest } \\
\text { Posttest }\end{array}$ & $1.145^{*}$ & $463^{*}$ \\
\cline { 2 - 5 } & CG & $\begin{array}{c}\text { Pretest } \\
\text { Posttest }\end{array}$ & .020 & $803^{*}$ \\
\hline
\end{tabular}

Fig. 1 shows the Means of the three types of assessments in posttests and pretests for EG and CG. The upper part displays the trends of mean values of the assessments in the pretest. The trends of mean values are more gently than those shown on the lower part in the posttest. The abrupt trends on the lower part indicate the great differences of assessments between the pretest and posttest in EG and CG. Therefore, the application of formative assessment with MAI has great effect on college English listening and speaking.

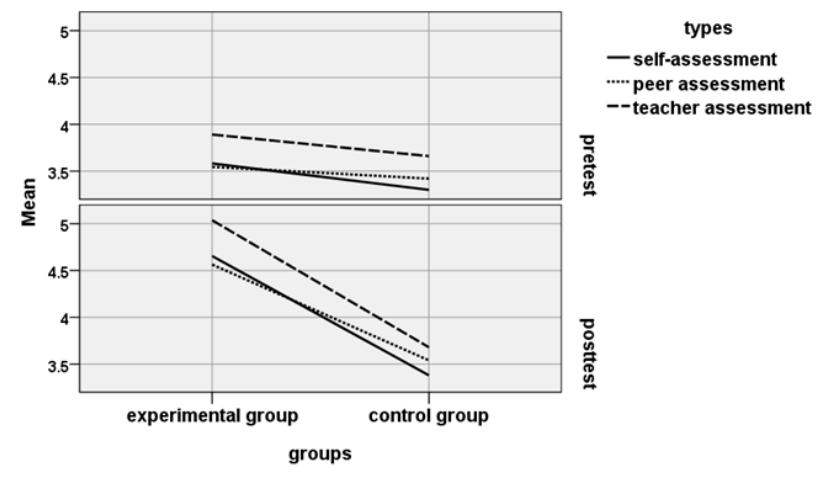

Fig. 1 Example of a figure caption

\section{CONCLUSION}

It is widely believed that computer assisted language learning (CALL) can provide a better learning environment for language learning. At present, the research and practice of CALL has received widespread attention in the world. However, there are still many blank areas waiting for us to explore. Among them, there are relatively few researches on listening and speaking in multimedia environment. In order to improve the quality of College English listening and speaking teaching, we must reform the former teaching mode and means, create a good communicative context of English listening and speaking, and cultivate the students' autonomous learning ability.

The formative assessment with MAI should reflect the principle of combining the practicality, knowledge and students' interest, and should fully inspire the enthusiasm of both teachers and students and establish the students' main position in the teaching process. College English listening and speaking classroom has entered a new development space due to the introduction of the formative assessment with MAI, which enables both teachers and students to enter the best state of harmonious teaching and learning.

Ethnic universities have their own characteristics. They have great difference with other universities, and students' understanding and attention to English learning are also inferior. Therefore, we cannot blindly copy the practice of teaching from other colleges and universities. Under the situation of introducing formative assessment with MAI in ethnic universities, the positive inquiry is imperative for the reform of College English listening and speaking teaching, and the exchange and cooperation between various ethnic colleges and universities are of great significance.

\section{REFERENCES}

[1] T. Crooks, "The Validity of Formative Assessments," British Educational Research Association Annual Conference, University of Leeds, pp. 13-15, September 2001.

[2] A. Huhta, "Diagnostic and Formative Assessment," In The Handbook of Educational Linguistics, Spolsky, Bernard, Hult, M. Francis, Eds. Oxford, UK: Blackwell, 2010, pp. 469-482.

[3] Shepard and A. Lorrie, "Formative assessment: Caveat empto," ETS Invitational Conference. The Future of Assessment: Shaping Teaching and Learning, New York, pp. 10-11, October 2005.

[4] P. Richard, Charting your course: How to prepare to teach more effectively, Atwood Publishing, 2000.

[5] W. Harlen and M. James, "Assessment and Learning: differences and relationships between formative and summative assessment," Assessment in Education: Principles, Policy \& Practice, vol. 4 (3), pp. 365-379, 1997.

[6] D. Nicol and D. Macfarlane-Dick, "Rethinking Formative Assessment in HE: a theoretical model and seven principles of good feedback practice," Quality Assurance Agency for Higher Education, 2005.

[7] D. Nicol and D. Macfarlane-Dick, "Formative assessment and selfregulated learning: a model and seven principles of good practice," Studies in Higher Education, vol. 31 (2), pp. 199-218, 2006.

[8] F. H. Tsai, C. C. Tsai, and K. Y. Lin, "The evaluation of different gaming modes and feedback types on game-based formative assessment in an online learning environment," Computers \& Education, vol. 81, pp. 259-269, 2015.

[9] L. A. Shepard, W. R. Penuel, and J. W. Pellegrino, "Using learning and motivation theories to coherently link formative assessment, grading practices, and large - scale assessment," Educational Measurement: Issues and Practice, vol. 37(1), pp. 21-34, 2018.

[10] C. M. Dudek, L. A. Reddy, A. Lewka, A. N. Hua, and G. A. Fabiano, "Improving universal classroom practices through teacher formative assessment and coaching," Assessment for Effective Intervention, $1534508418772919,2018$. 